\title{
NERVE CONDUCTION STUDY IN CHILDREN WITH INSULIN DEPENDENT DIABETES MELLITUS
}

\author{
Hannah John'1, Sahila M²
}

${ }^{1}$ Senior Resident, Department of Physiology, Government Medical College, Trivandrum, Kerala, India. 2Professor, Department of Physiology, Government Medical College, Trivandrum, Kerala, India.

\begin{abstract}
BACKGROUND
Type 1 diabetes is one of the most common childhood endocrine diseases that affects nearly five lakh children below the age group of fifteen years. Diabetic neuropathy (DN) consists of a large spectrum of abnormalities affecting both peripheral and autonomic nerve function. Electrophysiological studies (NCS and EMG) are powerful tools for assessing neuropathy. The aim of this study was to determine the prevalence of peripheral neuropathy (symptomatic and asymptomatic) in children suffering from Type 1 Diabetes Mellitus (IDDM) by means of an electrophysiological method.
\end{abstract}

ABSTRACT

\section{MATERIALS AND METHODS}

The present study is a hospital based cross sectional study done on 48 type 1 diabetes patients who attended the Paediatric Endocrinology clinic at the SAT Hospital, Thiruvananthapuram.

\section{RESULTS}

1. The prevalence of peripheral neuropathy, by means of an electrophysiological method, in 48 children suffering from type 1 DM with a mean duration of illness 3.9 yrs. and a mean HbA1c of $9.8 \%$ was found to be $37.5 \%$.

2. A clinical neuropathy with symptoms and signs was found in only $12.5 \%$ of the patients.

3. Lower limb nerves were found to be involved more frequently than upper limb nerves.

4. Sensory nerves were affected more frequently than motor nerves.

\section{CONCLUSION}

Electrophysiological studies should be done in all children with type 1 diabetes mellitus irrespective of their symptoms and signs of clinical neuropathy.

\section{KEY WORDS}

Type 1 Diabetes, Nerve Conduction Studies, Diabetic Neuropathy.

HOW TO CITE THIS ARTICLE: John H, Sahila M. Nerve conduction study in children with insulin dependent diabetes mellitus. J. Evolution Med. Dent. Sci. 2019;8(05):289-293, DOI: 10.14260/jemds/2019/64

\section{BACKGROUND}

Diabetes Mellitus (DM) is a diverse group of metabolic disorders characterized by chronic hyperglycaemia with disturbances of carbohydrate, protein and fat metabolism. The majority of cases of diabetes are divided into Type 1 and Type 2 diabetes. Interactions of genetic, environmental, and immunologic factors are responsible for type 1 Diabetes mellitus (T1DM). These factors ultimately lead to the destruction of the pancreatic beta cells and insulin deficiency. It usually arises during childhood and adolescence, with a peak incidence before school age and again at around puberty ${ }^{1}$. most, but not all, individuals with type 1 diabetes have evidence of islet-directed autoimmunity. T1DM eventually leads to dependence on insulin for survival.

Type 1 Diabetic mellitus is a significant disease. It is one of the most common paediatric endocrine illness that affects nearly 5 lakh children below 15 years of age worldwide. Of these more than 50 percent lives in developing countries. It is estimated that 97,700 children with T1DM lives in India.

'Financial or Other Competing Interest': None.

Submission 16-12-2018, Peer Review 21-01-2019,

Acceptance 28-01-2019, Published 04-02-2019.

Corresponding Author:

Dr. Sahila $M$

Professor,

Department of Physiology, Government Medical College,

Trivandrum, Kerala, India.

E-mail: drsahilagofour@yahoo.com

DOI: $10.14260 /$ jemds $/ 2019 / 64$
There is an increase in incidence of Type $1 \mathrm{DM}$ in children. Even though India and China have relatively low incidence rates for diabetes $(4.2$ and $0.6 / 100,000$ respectively) there is a high proportion of the world's children with type 1 diabetes because of their large populations. ${ }^{2}$

The concern regarding the number of new cases of diabetes is due to the development of chronic complications. It has been recognized for years that these complications cause considerable morbidity and mortality affect the quality of life in individuals with diabetes negatively with an increase in disability and death ${ }^{3}$.

There will be secondary pathophysiologic changes in multiple organ systems like the eyes, kidneys, nerves, heart and blood vessels due to metabolic dysregulation associated with DM. These changes include long-term damage, dysfunction, and failure of these organs. Complications of diabetes have been classified into micro vascular (i.e. retinopathy, nephropathy, and neuropathy) or macro vascular (i.e. cardiovascular disease, cerebrovascular accidents, and peripheral vascular disease).

Diabetic Neuronopathy constitute a large spectrum of abnormalities affecting both peripheral and autonomic nerve functions. Neuropathy is one of the most common and troublesome major complications afflicting those with Diabetes. ${ }^{4}$ It affects all types of Diabetes. 


\section{Definition}

A simple definition of diabetic neuropathy as per an international consensus meeting on the outpatient diagnosis and management of diabetic neuropathy was the presence of symptoms/or signs of peripheral nerve dysfunction in people with diabetes after exclusion of other causes. ${ }^{5}$

Frequently, the diagnosis of diabetic neuropathy is difficult to make because the manifestations are nonspecific and may occur in numerous other conditions. The disorder may manifest either clinically, through numerous different symptoms, or sub clinically, with abnormalities detectable only by careful testing. ${ }^{6}$

The most common neuropathic disorders are chronic sensorimotor diabetic peripheral neuropathy (DPN) and autonomic neuropathy. ${ }^{7}$ It may be silent and produce no symptoms. In some it progresses insidiously resulting in ulcers, amputations and fractures and seriously compromising quality of life and activities of daily living. ${ }^{8}$ Diabetic autonomic neuropathy causes substantial morbidity and increased mortality, particularly if cardiovascular impairment is present.

Subclinical Neuropathy

A latent, subclinical form of neuropathy with diabetes is observed in addition to the clinically manifest form. In subclinical diabetic neuropathy clinical examination findings will be normal but there will be abnormal electrophysiological studies. ${ }^{9}$

Studies show that in children and adolescents with T1DM peripheral neuropathy is prevalent, and in the majority of patients it is subclinical. Meh and Denislic found that the subclinical involvement of peripheral nervous system in diabetic children is $87 \% .^{10}$ Subclinical abnormalities in cardiovascular and gastrointestinal autonomic function may be found at diagnosis or even in teenage diabetic patients. ${ }^{11,12}$

\section{Clinical Neuropathy}

The clinically manifest form of diabetic neuropathy has been classified into the two broad categories of somatic and autonomic neuropathies.

The somatic neuropathies tend to fall into three major subdivisions: symmetric distal polyneuropathies, proximal motor neuropathies, and focal neuropathies. The autonomic neuropathies may involve any system in the body. Autonomic system abnormalities include pupillary abnormalities, cardiovascular abnormalities, motor disturbances of gastrointestinal tract, genitourinary tract disturbances, sweating disturbances and metabolic disturbances.

Nerve Conduction Studies (NCS)

NCS and EMG are important tools for diagnosis and research in patients with neuropathy. These tests assess the ability of the peripheral nerve to measure the strength and speed of electrical impulses propagated through the length of peripheral nerve.

The NCS consists of stimulation of motor or sensory nerves and recording the elicited CMAP (Compound muscle action potential) and SNAP (Sensory nerve action potential) respectively. The results are expressed as amplitudes, distal latencies and conduction velocities. In neuropathy screening NCS typically include testing of median and sensory nerves in one arm and tibial and peroneal motor and sural sensory in one leg. ${ }^{11}$
Electrophysiological assessment of nerve function by nerve conduction studies is a very sensitive and specific investigation, which can pick up impairment in asymptomatic patients also.

In summary even though the prevalence of DPN in children is high it has not received its attention it deserves. It severely affects the quality of life and causes significant morbidity. Therefore, DPN should be diagnosed early in the course of the disease. Since the predictive value and sensitivity of clinal examination is low routine NCS is warranted in all children with T1DM

Nerve conduction study was performed on 48 children with type $1 \mathrm{DM}$. The nerves tested were the peroneal and tibial motor nerves and the sural (Sensory) nerve in the right leg and the median and ulnar motor and sensory nerves in the right arm. The parameters measured were the distal latency, amplitude and nerve conduction velocities in the motor nerves and the peak latency, peak to base amplitudes and conduction velocities in the sensory nerves.

\section{Objectives of the Study}

- To compare the nerve conduction parameters in diabetic and non-diabetic children

- $\quad$ To determine the prevalence of peripheral neuropathy (symptomatic and asymptomatic) in children suffering from Ty1DM.

\section{MATERIALS AND METHODS}

\section{Study Design}

Hospital based observational study.

$$
\begin{aligned}
& \text { Sample size was calculated by using following formula } \\
& \mathrm{n}=\quad \mathrm{t} \alpha^{2} \mathrm{x} \sigma^{2} \\
& \mathrm{~d}^{2} \\
& \mathrm{n}=\text { Sample size } \\
& \sigma=\text { Power of standard deviation } \\
& \mathrm{d} \text { = Difference between } 2 \text { means } \\
& \text { Where } \mathrm{t} \alpha \text { at } 5 \% \mathrm{SL}=1.96 \\
& \sigma=10.45168 \\
& \mathrm{~d}=3 \text { units } \\
& 1.962 \times 10.452 \\
& =\quad 32 \\
& =47
\end{aligned}
$$

The sample size was calculated as 47 and fixed as 48

Study was done on 48 type 1 diabetic patients who attended the Paediatric Endocrinology clinic at the SAT Hospital, Thiruvananthapuram. An equal number of age and sex matched non-diabetic children were also included in the study for comparison.

\section{Study Centre}

Department of Paediatric Neurology, Sree Avittom Thirunal (SAT) Hospital, Thiruvananthapuram, Kerala. 


\section{Population}

Type 1 diabetic patients attending the Endocrinology outpatient clinic of the SAT Hospital, Thiruvananthapuram were taken as cases.

\section{Inclusion Criteria for Children with Type 1 Diabetes}

Children and adolescents between $4-16$ years of age with Type $1 \mathrm{DM}$, receiving insulin therapy.

\section{Exclusion Criteria for Children with Type 1 Diabetes} Evidence of any nutritional deficiencies.

- Any collagen tissue disease or malignancies.

- Any other neurological disease in the patient.

- Any familial or hereditary neurological disease history.

\section{Inclusion Exclusion Criteria for Non-Diabetic Children}

An equal number of age and sex matched non-diabetic children with no peripheral nerve disease attending the paediatric neurology OP of the SAT Hospital, Thiruvananthapuram for evaluation of headache or syncope were taken as the comparison group.

\section{Ethical Approval}

Research protocol was submitted to the Human Ethical Committee of the institution. The study commenced after getting the clearance from Human Ethical committee (IEC No: 08/30/2011/MCT). A written informed consent was obtained from parents of all patients included in the study.

\section{Study Method}

Details regarding the patient were collected which included name, age, gender, permanent address, IP Number, diabetic status, duration of diabetes, any symptoms of neuropathy and other complications of diabetes. These were obtained by an oral questionnaire method, case records and discussion with the concerned physician. Informed consent was obtained from the parents of each subjects (Both diabetic and nondiabetic children) after the procedures were fully explained. History of subjective neuropathy symptoms was taken in these patients and neurological examination was performed The subjective symptoms included pain, numbness, burning feet, and other types of sensory impairment (Pain, touch, and temperature), muscle weakness in the limbs, unsteadiness during walking etc.

A detailed neurological examination including superficial somatic sensations such as touch and pain and deep somatic sensations like vibration and joint position tests as well as muscle strength and deep tendon reflexes are done in all subjects.

\section{Touch Sensations}

The sense of fine touch was evaluated by touching the skin surface with a wisp of cotton. Crude touch was tested by touching the skin with a blunt object. Tactile localisation was tested by asking the patient to localize the site of touch. Tactile discrimination was tested by asking the patient to discriminate between two points touched simultaneously using a blunt divider as two separate points.

\section{Pain Sensations}

Superficial pain was tested with a pin prick. Deep pain was tested by squeezing the muscles and pinching the tendoachillles.

\section{Joint Position Test and Vibration}

To test the joint position, test the patient was asked to imitate a movement of the limb on the opposite side of the body wit eyes closed. Vibration test was done by using a $128 \mathrm{~Hz}$ tuning fork and placing it over malleolus in lower limb and projecting bone of the radius in upper limb.

\section{Reflexes}

Biceps, Triceps and supinator jerks were done on upper limbs and patellar and ankle jerks from lower limbs and motor power is evaluated by MRC grading.

\section{Neurophysiological Examination}

The Nerve conduction study of peripheral nerves involves the transcutaneous stimulation of motor or sensory nerves and recording of the elicited action potentials in the muscle (CMAP) and the sensory nerve (SNAP).

\section{Principle of Nerve Conduction Studies}

Peripheral nerves can be easily stimulated and brought to action potential with a brief electrical pulse applied to the overlying skin. The action potential is recorded by surface electrodes placed over the skin. Techniques have been described for studying most peripheral nerves.

\section{Nerves Studied}

The nerves studied are motor sensory and mixed nerves. They can be studied by stimulating the nerve with the recording electrode placed over the distal muscle, sensory cutaneous nerve or entire mixed nerve respectively.

The findings of the motor, sensory and mixed nerve studies often complement one another. Depending on the underlying pathology they yield different types of information associated with distinct patterns of abnormalities. In the present study, the standard nerve conduction measurements were performed on the following nerves.

\section{Right Upper Limb}

1. Median motor and sensory nerves.

2. Ulnar motor and sensory nerves.

\section{Right Lower Limb}

1. Common peroneal nerve.

2. Tibial motor nerve.

3. Sural sensory nerve.

Studies were performed with a standard technique using surface electrodes. Motor nerve conduction velocity (MCV), CMAP amplitude and distal motor latency (DML) were determined in the motor nerves. Sensory nerve conduction velocity (SCV), peak latency and SNAP amplitude were determined in the sensory nerves.

The results of these motor and sensory NCS expressed as amplitude distal latencies and conduction velocities provide certain quantitative and qualitative information that cannot be obtained by a neurological examination. ${ }^{12}$ The criteria for peripheral nerve involvement is at least 2 abnormal independent neurophysiological nerve parameters in a single nerve. ${ }^{9}$ 


\section{Data Analysis}

Data analysis was performed by SPSS (Version 17) for windows. Alpha value was set as 0.05 . Unpaired t test was used to compare NCV parameters of diabetic children with non-diabetics. Qualitative data were expressed in Percentages and numbers. Microsoft excel, word was used to generate graph and tables.

\section{RESULTS}

The mean age in diabetic group was 11.0 with a standard deviation of 2.5 and in non-diabetic group mean age were 10.6 with standard deviation of 1.7 . There were 22 males and 26 females in the diabetic group and 26 males and 22 females in non-diabetic group. Results showed that while comparing distal latency of diabetic children with non-diabetic children, only median nerve latency was more compared to nondiabetics which were statistically significant (Table I). The amplitude (CMAP) of all nerves was less in diabetics compared to non-diabetics which were statistically significant (Table II). The conduction velocity (MNCV) of all nerves was less in diabetics compared to non-diabetics which were statistically significant (Table III). The sensory peak latency of all nerves was more in diabetics compared to nondiabetics which were not statistically significant (Table IV). While comparing amplitude (SNAP) of diabetic children with non-diabetic children, only sural nerve amplitude was less compared to non-diabetics which were statistically significant (Table V). The sensory nerve conduction velocity (SNCV) of all nerves was less in diabetics compared to nondiabetics. But only for sural and ulnar nerve, values were statistically significant (Table III).

\begin{tabular}{|c|c|c|c|c|c|}
\hline $\begin{array}{c}\text { Sl. } \\
\text { No. }\end{array}$ & Nerve & Diabetic & $\begin{array}{c}\text { Non- } \\
\text { Diabetic }\end{array}$ & T-Value & p-Value \\
\hline 1 & Median N & $2.88 \pm 0.60$ & $2.63 \pm 0.49$ & 2.283 & 0.025 \\
\hline 2 & Ulnar N & $2.11 \pm 0.47$ & $2.00 \pm 0.31$ & 1.323 & 0.189 \\
\hline 3 & CPN & $3.7 \pm 1.11$ & $3.6 \pm 0.64$ & 0.65 & 0.52 \\
\hline 4 & Tibial N & $3.3 \pm 0.76$ & $3.4 \pm 0.67$ & -1.2 & 0.23 \\
\hline
\end{tabular}

Table I. Comparison of Distal Latency of Diabetic and NonDiabetic Children

\begin{tabular}{|c|c|c|c|c|c|}
\hline $\begin{array}{c}\text { Sl. } \\
\text { No. }\end{array}$ & Nerve & Diabetic & $\begin{array}{c}\text { Non- } \\
\text { Diabetic }\end{array}$ & $\begin{array}{c}\text { T- } \\
\text { Value }\end{array}$ & p-Value \\
\hline 1 & $\begin{array}{c}\text { Median } \\
\text { Motor }\end{array}$ & $10.66 \pm 4.58$ & $13.13 \pm 3.54$ & -2.959 & 0.004 \\
\hline 2 & Ulnar Motor & $8.3 \pm 2.8$ & $11.1 \pm 3.7$ & -4.181 & 0.001 \\
\hline 3 & CPN & $4.7 \pm 3.8$ & $6.8 \pm 3.0$ & -2.957 & 0.004 \\
\hline 4 & Tibial Nerve & $11.2 \pm 4.4$ & $17.1 \pm 7.6$ & -4.678 & 0.001 \\
\hline \multicolumn{7}{|c|}{ Table II. Comparison of CMAP Amplitude of Diabetic and } \\
Non-Diabetic Children \\
\hline
\end{tabular}

\begin{tabular}{|c|c|c|c|c|c|}
\hline $\begin{array}{c}\text { Sl. } \\
\text { No. }\end{array}$ & Nerve & Diabetic & $\begin{array}{c}\text { Non- } \\
\text { Diabetic }\end{array}$ & T-Value & p-Value \\
\hline 1 & Median N & $55.29 \pm 7.58$ & $60.03 \pm 6.88$ & -3.220 & 0.002 \\
\hline 2 & Ulnar N & $55.0 \pm 8.3$ & $58.7 \pm 7.9$ & -2.231 & 0.028 \\
\hline 3 & CPN & $45.5 \pm 8.6$ & $51.1 \pm 4.6$ & -4.016 & 0.001 \\
\hline 4 & Tibial N & $42.7 \pm 5.5$ & $48.0 \pm 5.3$ & -4.831 & 0.001 \\
\hline \multicolumn{6}{|c|}{ Table III. Comparison of MNCV of Diabetic and Non- } \\
Diabetic Children \\
\hline
\end{tabular}

\begin{tabular}{|c|c|c|c|c|c|}
\hline $\begin{array}{c}\text { Sl. } \\
\text { No. }\end{array}$ & Nerve & Diabetic & $\begin{array}{c}\text { Non- } \\
\text { Diabetic }\end{array}$ & T-Value & p-Value \\
\hline 1 & Median N & $3.05 \pm 1.14$ & $2.78 \pm 0.46$ & 1.505 & 0.136 \\
\hline 2 & Ulnar N & $2.8 \pm 1.3$ & $2.6 \pm 0.5$ & 0.971 & 0.334 \\
\hline 3 & Sural N & $2.50 \pm 1.4$ & $2.43 \pm 0.55$ & 0.305 & 0.761 \\
\hline \multicolumn{7}{|c|}{ Table IV. Comparison of Sensory Peak Latency of Diabetic } \\
and Non-Diabetic Children \\
\hline
\end{tabular}

\begin{tabular}{|c|c|c|c|c|c|}
\hline $\begin{array}{c}\text { Sl. } \\
\text { No. }\end{array}$ & Nerve & Diabetic & Non-Diabetic & T-Value & p-Value \\
\hline 1 & $\begin{array}{c}\text { Median } \\
\text { Sensory }\end{array}$ & $28.60 \pm 17.86$ & $32.81 \pm 11.87$ & 0.204 & 0.839 \\
\hline 2 & $\begin{array}{c}\text { Ulnar } \\
\text { Sensory }\end{array}$ & $26.9 \pm 19.7$ & $26.2 \pm 12.2$ & 0.204 & 0.839 \\
\hline 3 & Sural & $13.4 \pm 11.1$ & $17.5 \pm 5.7$ & -2.251 & 0.027 \\
\hline \multicolumn{6}{|c|}{ Table V. Comparison of SNAP amplitude of diabetic and } \\
non-diabetic children \\
\hline
\end{tabular}

\begin{tabular}{|c|c|c|c|c|c|}
\hline $\begin{array}{c}\text { Sl. } \\
\text { No. }\end{array}$ & Nerve & Diabetic & Non-Diabetic & $\begin{array}{c}\text { T- } \\
\text { Value }\end{array}$ & $\begin{array}{c}\text { p- } \\
\text { Value }\end{array}$ \\
\hline 1 & $\begin{array}{c}\text { Median } \\
\text { Sensory }\end{array}$ & $52.11 \pm 29.94$ & $52.9 \pm 8.9$ & -0.174 & 0.863 \\
\hline 2 & $\begin{array}{c}\text { Ulnar } \\
\text { Sensory }\end{array}$ & $47.17 \pm 9.92$ & $54.2 \pm 10.26$ & -3.406 & 0.001 \\
\hline 3 & Sural & $49.6 \pm 36.9$ & $61.8 \pm 9.6$ & -2.214 & 0.029 \\
\hline
\end{tabular}

Table VI. Comparison of Sensory NCV Of Diabetic and NonDiabetic Children

Out of the 48 patients, 18 (37.5\%) were found to have peripheral neuropathy as determined by means of electrophysiological methods. Of these only $6(12.5 \%)$ had associated symptoms. Of these $44.4 \%$ cases with DPN were males and $55.6 \%$ were females.

Out of the 48 patients, $18(37.5 \%)$ were found to have peripheral neuropathy as determined by means of electrophysiological methods. Of these only $6(12.5 \%)$ had associated symptoms. Of these $44.4 \%$ cases with DPN were males and $55.6 \%$ were females.

\begin{tabular}{|c|c|}
\hline Nerves Involved & Percentage \\
\hline Sural & 16.6 \\
\hline Ulnar Sensory & 10.41 \\
\hline Median Sensory & 6.25 \\
\hline Ulnar Motor & 6.25 \\
\hline Median Motor & 4.16 \\
\hline Common Peroneal Nerve & 4.16 \\
\hline Tibial & 2.08 \\
\hline
\end{tabular}

Analysis showed that the sural sensory nerve was the most frequently involved nerve (16.6\%) followed by the ulnar sensory (10.41\%) and median sensory (6.25\%).

\begin{tabular}{|c|c|c|}
\hline No. of Nerves Involved & Frequency & Percentage \\
\hline 0 & 30 & 62.5 \\
\hline 1 & 13 & 27.1 \\
\hline 2 & 4 & 8.3 \\
\hline 3 & 1 & 2.1 \\
\hline Total & 48 & 100.0 \\
\hline \multicolumn{3}{|c|}{$\begin{array}{c}\text { Table VII. Percentage Distribution of Number of Nerves } \\
\text { Involved }\end{array}$} \\
\hline
\end{tabular}

Out of the 48 patients, $27.1 \%$ had abnormal nerve conduction in only 1 nerve, $8.3 \%$ had abnormal nerve 
conduction in 2 nerves and $2.1 \%$ had abnormalities in 3 nerves.

\section{DISCUSSION}

Diabetic neuropathy (DN) is a set of heterogeneous clinical syndromes that affect distinct regions of the nervous system, singly or combined. Among the most common long-term complications of diabetes, DN is a significant source of morbidity. It appears that the most rapid deterioration of nerve function occurs soon after the onset of type 1 diabetes, and within 2-3 yrs., there is a slowing of the progress.

In clinical practice, the presence of symptoms and signs defines diabetic neuropathy, but a more accurate diagnosis requires the presence of electrophysiological abnormalities. Previously published consensus statements advocate nerve conduction studies as the method of choice because these are sensitive, specific, and validated measures of the presence of nerve function impairment.

Nerve dysfunction early on in the disease predicts clinical neuropathy several years later, so it is important to diagnose neuropathy in diabetic children early enough to prevent further progress of the disease. Though diabetic neuropathy has been extensively studied in adults, studies in children with type 1 diabetes are few.

The present study had the following salient features-

1. The prevalence of peripheral neuropathy, by means of an electrophysiological method, in 48 children suffering from type $1 \mathrm{DM}$ was found to be $37.5 \%$.

2. A clinical neuropathy with symptoms and signs was found in only $12.5 \%$ of the patients.

3. Both sensory nerve conduction velocity (SNCV) \& motor nerve conduction velocity (MNCV) of all nerves was less in diabetics compared to non-diabetics.

4. Lower limb nerves were found to be involved more frequently than upper limb nerves.

5. Sensory nerves were affected more frequently than motor nerves.

6. Sural sensory nerve was the most frequently involved nerve.

\section{CONCLUSION}

Electrophysiological studies should be done in all children with type 1 diabetes mellitus irrespective of their symptoms and signs of clinical neuropathy.

\section{REFERENCES}

[1] German MS. Greenspan's Basic and clinical endocrinology. $8^{\text {th }}$ edn. San Francisco: The McGrawHill Companies 2007.

[2] Gale EAM. Epidemiology of type 1 diabetes [internet]. 2012 [cited 2013 Oct 28], Diapedia 2104085168 rev. no. 39. http://www.diapedia.org/type-1-diabetesmellitus/2104085168/epidemiologyof-type-1-

diabetes.

[3] Nathan DM, Cagliero E. Diabetes mellitus. In: Felig P, Frohman LA, eds. Endocrinology and metabolism. 4th edn. New York: McGraw-Hill 2001.

[4] Karsidag S, Morali S, Sargin M, et al. The electrophysiological findings of subclinical neuropathy in patients with recently diagnosed type 1 diabetes mellitus. Diabetes Research and Clinical Practice 2005;67(3):211-9.

[5] American Diabetes Association and American Academy of Neurology. Consensus statement: report and recommendations of the San Antonio conference on diabetic neuropathy. Diabetes Care 1988;11(7):592-7.

[6] Vinik AI, Holland MT, Le Beau JM, et al. Diabetic neuropathies. Diabetes Care 1992;15(12):1926-75.

[7] American Diabetes Association. Standards of medical care in diabetes - 2010. Diabetes Care 2010;33 Suppl 1:S11-S61.

[8] Vinik AI. Neuropathies in children and adolescents with diabetes: the tip of the iceberg. Pediatric Diabetes 2006;7(6):301-4.

[9] Eeg-Olofsson 0, Petersen I. Childhood diabetic neuropathy a clinical and neurophysiological study. Acta Pediatrica Scandinavica 1966;55(2):163-76.

[10] Hoeliner I, Haslinger V, Lütschg J, et al. 1512 Validity of the clinical neurological state in diagnosing diabetic peripheral neuropathy. Arch Dis Child 2012;97(Suppl 2):A428-A9.

[11] Brownlee M, Aiello LP, Cooper ME, et al. Complications of diabetes mellitus. In: Kronenberg HM, Melmed S, Polonsky KS, et al. eds. William's Textbook of endocrinology. 11 th edn. Philadelphia: Saunders Elsevier 2008: p. 1417-501.

[12] Gooch CL, Weimer LH. The electrodiagnosis of neuropathy: basic principles and common pitfalls. Neurol Clin 2007;25(1):1-28. 